\title{
LEVANTAMENTO DOS RISCOS EXISTENTES À SEGURANÇA E À SAÚDE DO TRABALHADOR NA PÓS-COLHEITA DE CAFÉ (Coffea arabica) CONFORME AS EXIGÊNCIAS DAS NORMAS REGULAMENTADORAS
}

\author{
Survey of the existing risks to the security and health of the worker in the after harvesting of \\ the coffee plant (Coffea arabica) by according to the requirements of regulatory norms
}

\author{
Cinara da Cunha Siqueira Carvalho ${ }^{1}$, Flávio Meira Borém², Giovanni Francisco Rabelo ${ }^{3}$
}

\begin{abstract}
RESUMO
A segurança no trabalho é um tema que vem chamando muito a atenção do setor agrícola, devido à sua importância como um dos itens considerados para a aquisição da certificação, que agrega valor ao café e conseqüentemente, melhora o preço para o produtor. Considerando a existência dos riscos em todas as atividades e a falta de percepção por parte do empregador e do trabalhador no processo de pós-colheita do café, bem como a falta de conformidade das propriedades quanto à aplicação das normas regulamentadoras do Ministério do Trabalho e do Emprego (M.T.E), o objetivo deste trabalho foi diagnosticar os riscos envolvidos em cada uma das etapas da pós-colheita do café e sua percepção por parte dos trabalhadores e proprietários. Além disso, precisamos verificar se unidades de processamento de café estão em conformidade com as normas regulamentoras, a fim de determinar os pontos de risco que levem os órgãos governamentais a auxiliar os produtores na modificação do processo para possibilitar a exportação do café. O trabalho foi realizado a partir da aplicação de questionário em trinta propriedades localizadas em três associações rurais do município de São Sebastião do Paraíso - MG, definidas por sorteio. A análise dos questionários mostrou que, somente 23\% das pessoas entrevistadas possuíam percepção dos riscos existentes nas propriedades e somente 3\% delas estavam dentro dos padrões de conformidade com as NR's. Esses dados estão relacionados ao baixo nível tecnológico, à falta de treinamento dos funcionários e às dificuldades de acesso à informação por parte dos produtores.
\end{abstract}

Termos para indexação: Ergonomia e segurança, certificação, café.

\section{ABSTRACT}

The security in the work is a subject that has calling the attention of the agricultural sector, due to its importance as one of itens considered for the acquisition of the certification, which aggregates value to the coffee plant and consequently improves the price for the producer. Considering the existence of the risks in all the activities and the lack of perception by the employer and the worker in the process of after harvesting of the coffee plant, as well as the non conformance of the farms concerning the application of the Regulatory Norms of the Ministry of Labor and Employment (M.L.E), the objective of this work was to diagnose the involved risks in each one of the stages of the after harvesting of the coffee plant and its perception by the workers and farmers. Moreover, to verify if units of coffee processing are in compliance with the regulatory norms, in order to determine the risk points that would be interesting for governmental organs to assist the producers in the modification of the process to make possible the exportation of the coffee. The work was carried out from the application of questionnaire in thirty properties located in three agricultural associations in the São Sebastião do Paraíso county - MG defined by assartment. The analysis of the questionnaires showed that only $23 \%$ of the interviewed people had perception of the existing risks in the farms and only $3 \%$ of the farms were in accordance with the standards of conformity with the NR's. These data are related to the low technological level, to the lack of training of the workers and to the difficulties of accessing the information by of the producers.

Index terms: Ergonomics and security, certification, coffee.

(Recebido em 19 de abril de 2005 e aprovado em 1 de setembro de 2006)

\section{INTRODUÇÃO}

Dentro da agricultura, a segurança no trabalho é um tema que vem chamando muito a atenção de produtores e pesquisadores devido à crescente preocupação com a qualidade total e por ser um dos itens exigidos por empresas certificadoras para a realização da exportação (LACERDA, 1998), além da preocupação com a preservação do meio ambiente e a manutenção da qualidade do produto. A segurança no trabalho visa a realização das atividades sem

\footnotetext{
Engenheira Agrícola, Doutoranda - Departamento de Engenharia Agrícola/DEA - Universidade Federal de Viçosa/UFV - Av. PH Rolfs, s/n, 36570-000 Campus Universitário - Viçosa, MG - cinarasiqueira@yahoo.com.br - Projeto financiado pelo CNPq

${ }^{2}$ Engenheiro Agrônomo, Doutor, Professor Adjunto - Departamento de Engenharia Agrícola/DEG - Universidade Federal de Lavras/UFLA - Cx. P. 3037 37200-000 - Lavras, MG - flavioborem@ufla.br

${ }^{3}$ Engenheiro Eletricista, Doutor, Professor Adjunto - Departamento de Engenharia Agrícola/DEG - Universidade Federal de Lavras/UFLA - Cx. P. 3037 37200-000 - Lavras, MG - giovannirabelo@yahoo.com.br
} 
oferecer riscos à saúde e à segurança do trabalhador, possibilitando assim, um bem estar físico, mental e social nas condições e na organização dos processos de trabalho (BINDER et al., 2001; MACHADO \& GOMES, 1994; PERES et al., 2004). Esta situação tem levado os cafeicultores, juntamente com as instituições públicas e privadas, a aplicarem as Normas Regulamentadoras (NR) do Ministério do Trabalho e do Emprego e as Boas Práticas de Cultivo e Preparo (BPP) (CHALFOUN et al., 2003; PANALIMENTOS, 2003) no intuito de obter a certificação de qualidade (GLOBAL EXCHANGE, 2004), e assim alcançar melhores preços para o café, a partir da comercialização de um produto que deixa de ser uma "commodity" e que passa a possuir valores agregados na sua contextualização. O empregador se sente muito pressionado por questões econômicas e sociais e para sobreviver como empresa em um mercado competitivo, é necessário aumentar sua produção, melhorar a qualidade e reduzir os impactos ambientais. Durante a realização das etapas de pós-colheita do café, muitas atividades estão sujeitas ao cumprimento de uma série de regulamentações ambientais e sociais (aplicação das NRR's), exigências da certificação ISO entre outras. Percebe-se que as poucas empresas agrícolas que cumprem estas regulamentações preocupam-se, prioritariamente, com a etapa de produção.

Neste contexto, o objetivo deste trabalho foi diagnosticar os riscos à saúde e à segurança do trabalhador envolvidos em cada uma das etapas da pós-colheita do café, bem como avaliar a percepção dos riscos pelos trabalhadores e a conformidade das unidades de processamento do café às normas regulamentadoras do Ministério do Trabalho e do Emprego.

\section{MATERIAL E MÉTODOS}

O trabalho foi realizado no Departamento de Engenharia Agrícola da Universidade Federal de Lavras e na Cooperativa Agrícola de São Sebastião do Paraíso COOPARAÍSO, durante o mês de julho de 2004.

Foram aplicados questionários em 30 propriedades pertencentes a três associações rurais do município de São Sebastião do Paraíso - MG. O proprietário ou gerente foi entrevistado de acordo com um questionário proposto. Além disso foram realizadas observações "in loco" e registros fotográficos das propriedades visitadas analisados em função do nível tecnológico da propriedade. Esse foi definido em função das tecnologias e tratos culturais realizados, porcentagem de uso de mão-de-obra familiar, métodos de realização das atividades de processamento do café e máquinas utilizadas durante essas atividades. As propriedades que não realizavam todos os tratos culturais, não possuíam maquinário específico para o processamento e não realizavam todas as etapas na fazenda foram classificadas em nível tecnológico baixo. As propriedades que realizavam todos os tratos culturais, processavam o café no local, tinham maquinário específico para as atividades mas que possuíam instalações em estado regular de conservação, não forneciam treinamento para os funcionários e não se preocupavam com a preservação do meio ambiente, foram classificadas em nível tecnológico médio. As propriedades que realizavam todos os tratos culturais, possuíam maquinário e instalações para a realização de todas as atividades e encontravam-se em ótimo estado de conservação, forneciam treinamento para os funcionários e tinham preocupação com a preservação do meio ambiente, foram classificadas em nível tecnológico alto.

A análise dos riscos foi observada nas etapas de recepção, separação, secagem, armazenamento e beneficiamento por meio da observação "in loco" dos seguintes itens em cada uma das etapas: ruído, contato com a umidade, iluminação e poeira, presença de roedores, morcegos e pombos, presença ou ausência de extintor de incêndio, forma de empilhamento das sacas, estado de conservação dos fios elétricos, presença ou ausência de estruturas de proteção contra quedas, riscos ocultos, utilização de EPI's, fonte de aquecimento dos secadores, estado de conservação das benfeitorias, máquinas e equipamentos, destino dos resíduos sólidos e líquidos, consumo de água na separação e lavação, realização de exames médicos periódicos, treinamento das atividades realizadas, percepção dos trabalhadores quanto aos riscos de acidentes, tempo de exposição solar, equipamentos e ferramentas utilizadas na movimentação do café no terreiro.

Os dados coletados foram analisados segundo a estatística descritiva. As variáveis qualitativas foram estratificadas em classes como excelente, boa, ruim e péssima e apresentada por meio de tabelas de freqüência e gráficos, em porcentagem. As variáveis quantitativas foram apresentadas em forma de porcentagem.

\section{RESULTADOS E DISCUSSÃO}

Quanto à estrutura agrária das propriedades visitadas, a área cultivada em média foi de 56ha, ocorrendo $70 \%$ de propriedades com área cultivada inferior a 50ha. Com relação ao número de plantas cultivadas, a média foi de 154.000 pés de café. Somente $23 \%$ das propriedades possuíam um número de plantas cultivadas acima de 100.000 pés. A produção média de café foi de 1.300 sacas. Cerca de $67 \%$ dos entrevistados produziam menos de 500 sacas por ano. 
Com relação ao nível tecnológico, das 30 propriedades visitadas somente $47 \%$ realizam todas as atividades relacionadas aos tratos culturais como: análise de solo, análise foliar, adubação, correção do pH do solo e controle de pragas e doenças. A partir da realização dos tratos culturais, maquinário e forma de realização das etapas da pós-colheita foi possível separar as propriedades quanto ao nível tecnológico e estratificá-las em baixo, médio e alto, de acordo com o demonstrado na Tabela 1.

Tabela 1 - Porcentagem de propriedades visitadas quanto ao nível tecnológico.

\begin{tabular}{cc}
\hline Nível tecnológico & $\begin{array}{c}\text { Porcentagem de } \\
\text { propriedades } \\
\text { visitadas (\%) }\end{array}$ \\
\hline Baixo & 80 \\
Médio & 10 \\
Alto & 10 \\
\hline
\end{tabular}

A mão-de-obra que predomina nas propriedades visitadas é a familiar ocorrendo em $87 \%$ das propriedades visitadas. A porcentagem de fazendas que possuíam trabalhadores contratados é de $30 \%$.

A porcentagem de propriedades visitadas em que as pessoas possuíam percepção dos riscos foi de $23 \%$, os demais consideram que nenhuma atividade oferece risco. Observou-se que a maior limitação foi a questão cultural. $87 \%$ dos entrevistados, apesar de alguns não relatarem a percepção dos riscos, reclamaram de dores físicas provocadas pelas atividades realizadas.

Em virtude da existência dos riscos e da obrigatoriedade imposta pelo Ministério do Trabalho e do Emprego, é muito importante que exames médicos sejam realizados periodicamente, principalmente em trabalhadores que têm contato direto com produtos químicos, poeira, umidade, radiação solar ou que sentem dores no corpo. No entanto, somente $17 \%$ das propriedades cumprem a obrigação, com seus trabalhadores, de realizar exames médicos periódicos, feitos por empresas especializadas em segurança e medicina do trabalho. Nas demais propriedades visitadas os proprietários e funcionários fazem exames médicos somente quando sentem alguma dor ou outro sintoma relacionado à doenças. Esse comportamento entra em contradição com o que é recomendado pela NR 7 da Portaria $\mathrm{n}^{\circ} 3.214$ de 8 de junho de 1978, que fala sobre o Programa de Controle Médico de Saúde Ocupacional
(PCMSO), e descreve a realização obrigatória de exames médicos (BRASIL, 1978).

Com relação às instalações, das 30 propriedades visitadas, somente $17 \%$ possuíam moega de recepção no lavador. Somente $10 \%$ tinham ângulo de inclinação, recomendado para facilitar a movimentação e queda do café até o lavador. Os ângulos encontrados foram: $7 \%$ das moegas com $45^{\circ}$ de inclinação e $3 \%$ com $90^{\circ}$. Todas as moegas eram de alvenaria, mas somente duas tinham grade metálica de proteção na superfície e dessas duas, somente uma tinha as grades também nas laterais. Em somente 3\% das propriedades a moega possuía barras metálicas na superfície e nas extremidades, mas não estava de acordo com o ângulo de inclinação. O principal risco observado foi o risco de queda, devido à falta de segurança e proteção das moegas, além do risco existente de perda de qualidade do café, principalmente nas moegas em que o produto fica retido no fundo da estrutura, podendo desenvolver processo de fermentação. A Norma Regulamentadora recomendada para construção de moegas com segurança é a NR 8 da Portaria n³ 3.214 de 8 de junho de 1978 (BRASIL, 1978), onde estruturas que não são vedadas por paredes externas, devem dispor de guarda-corpo de proteção contra quedas e ser de material rígido, capaz de resistir aos grandes esforços aplicados no seu ponto mais desfavorável.

Após o escoamento do café pela moega ele chega até o lavador mecânico. A porcentagem de propriedades visitadas que possuíam o equipamento é de $17 \%$, sendo que, destes, somente $3 \%$ estavam com todo o conjunto em excelente estado de conservação. No entanto, em todas as propriedades o funcionamento deste equipamento gerava ruído elevado e em somente $3 \%$ das propriedades os funcionários estavam usando protetor auricular. A falta de proteção e segurança observada em algumas polias que estavam expostas, ofereciam riscos de acidentes mecânicos, que poderiam ser evitados a partir da implantação da NR 12 da Portaria n³.214 de 8 de junho de 1978 (BRASIL, 1978). A área que serve de circulação em torno de máquinas e equipamentos deve ser dimensionada e mantida de forma que o produto e os trabalhadores possam movimentar-se com segurança. Outro risco existente na área de separação do café é o acionamento e estado de conservação do painel de comando. As máquinas e os equipamentos devem ter dispositivos de acionamento e parada localizados de modo que possam ser acionados ou desligados pelo funcionário na sua posição de trabalho e por outro funcionário que não seja o responsável pelo funcionamento do equipamento; não esteja instalado em área perigosa da máquina ou do equipamento; não possa ser acionado ou desligado, involuntariamente, pelo operador ou de qualquer outra forma acidental e não ofereça riscos. 
Somente $17 \%$ das propriedades possuíam painel de comando e, em $60 \%$, o painel estava em péssimo estado de conservação. A realização das atividades relacionadas ao processo de separação expõe o trabalhador a contato prolongado com a umidade o que favorece o aparecimento de doenças. Esse risco pode ser evitado se o trabalhador utilizar EPI e roupas agasalhadas, conforme a NR 6 e NR 4 da Portaria $\mathrm{n}^{\circ} 3.067$ de 12 de abril de 1988, além da conservação e manutenção periódica do lavador (BRASIL, 1988).

Em $83 \%$ das propriedades lava-se somente o café de varrição. $20 \%$ dos produtores entrevistados adotam um sistema para retirar as impurezas do café que consiste em deixar o café de molho no desvio do córrego para retirar o excesso de terra e outras impurezas; em seguida ele segue por uma canaleta e cai na carroceria do trator, enquanto a água é despejada sobre o solo e segue até o córrego. Além dos riscos de contaminação do lençol freático e córregos, esse método oferece riscos de queda e doenças em virtude do contato excessivo com a água. Mas a maioria dos entrevistados (64\%) deixa o café de varrição de molho em caixas d'água ou banheiras. Foi observado um melhor aproveitamento das folhas e cascas do café, e em $100 \%$ das propriedades estes resíduos foram levados para a lavoura.

No processo de secagem no terreiro, ferramentas e máquinas são utilizadas para movimentar o café e a má utilização delas pode causar problemas ergonômicos e lombalgia no trabalhador, além dos riscos existentes à exposição solar. As ferramentas mais utilizadas são: rodo em $100 \%$ das propriedades, vassoura em $70 \%$ e trator em $23 \%$ das fazendas. De acordo com o item 21.2 da NR 21 da Portaria $\mathrm{n}^{\circ} 3.214$ de 8 de junho de 1978, devem ser exigidas medidas e equipamentos de proteção individual, que protejam os trabalhadores contra a insolação excessiva, o calor, o frio, a umidade e os ventos inconvenientes. $\mathrm{O}$ único EPI utilizado por $100 \%$ dos trabalhadores entrevistados foi o boné. No entanto, de acordo com a NR 4 da Portaria n 3.067 de 12 de abril de 1988, os trabalhadores expostos à radiação solar devem usar chapéu de palha de abas largas e cor clara para proteção contra o sol, chuva e salpicos. Dos funcionários que trabalhavam com o trator nenhum usava protetor auricular, recomendado pela NR 4. Além disso, nenhum trator possuía cabine de proteção, sendo que para o item 18.22.4 da NR 18, as máquinas e equipamentos devem proteger adequadamente o operador contra a incidência de raios solares e intempéries. Além da exposição solar, dores físicas foram relatadas por $27 \%$ dos entrevistados, em função do peso dos rodos e postura inadequada dos operadores durante as atividades com o trator.

Além dos riscos inerentes à segurança e à saúde do trabalhador, existe também o risco de perda da qualidade do produto. $\mathrm{O}$ ângulo de inclinação do terreiro e o tipo de revestimento interferem na manutenção da qualidade final do café. Somente $23 \%$ dos terreiros possuíam inclinação, que variava de 0,5 a $1 \%$ - valores que estão dentro do recomendado. Os terreiros mais indicados para a preservação das características do café são os de tijolos, concreto e lama asfáltica. A Tabela 2 traz a relação entre o nível tecnológico dos produtores e o tipo de terreiro utilizado por eles, em função do tipo de revestimento.

Constatou-se por meio da Tabela 2 um número maior de terreiros de concreto e tijolo nas propriedades onde o nível tecnológico era baixo, devido à quantidade de propriedades desse nível que foram visitadas. No entanto, em propriedades de nível tecnológico alto, não foi encontrado nenhum terreiro de chão batido, porque eram melhores as condições financeiras dos produtores que, conseqüentemente, possuem uma maior preocupação com a manutenção da qualidade do café.

$\mathrm{O}$ processo de secagem mecânico foi observado em somente $30 \%$ das propriedades visitadas. A quantidade e o tipo de secadores mais encontrados estão descritos na Tabela 3.

Observa-se que, quanto maior o nível tecnológico, maior o número de secadores existentes nas propriedades, o que pode ser explicado em função da maior capitalização e acesso à tecnologia por parte dos produtores.

Tabela 2 - Relação entre o nível tecnológico das propriedades: porcentagem e tipo de revestimento dos terreiros encontrados.

\begin{tabular}{ccccc}
\hline \multirow{2}{*}{ Nível Tecnológico } & \multicolumn{5}{c}{ Tipo de Revestimento } \\
\cline { 2 - 5 } & Concreto & Chão batido & Tijolo & Lama asfáltica \\
\hline Alto & 27 & - & 20 & - \\
Médio & 4 & - & - & - \\
Baixo & 69 & 100 & 80 & - \\
\hline
\end{tabular}


Tabela 3 - Relação entre a quantidade, tipo de secadores encontrados e o nível tecnológico das comunidades visitadas no município de São Sebastião do Paraíso - MG.

\begin{tabular}{ccc}
\hline \multirow{2}{*}{ Nível tecnológico } & \multicolumn{2}{c}{ Número de secadores } \\
\cline { 2 - 3 } & Rotativo & Vertical \\
\hline Alto & 13 & 1 \\
Médio & - & 3 \\
Baixo & - & - \\
\hline
\end{tabular}

Os tipos de combustíveis utilizados nos secadores são lenha (59\% dos secadores) e gás (41\%). Para utilização da lenha como fonte de combustível é necessário que o proprietário tenha a autorização do IEF (Instituto Estadual de Florestas) e somente $12 \%$ das propriedades possuíam essa autorização. Em 17\% das fazendas a lenha era oriunda do próprio local.

O principal risco existente para o trabalhador em locais onde se encontram os secadores é o risco de explosão e incêndios, principalmente nos secadores, por causa do pó que fica em suspensão. Para reduzir os riscos de incêndios, algumas medidas devem ser adotadas: a aplicação da NR 19 da Portaria n³.214 de 8 de junho de 1978 (BRASIL, 1978): nos locais onde são armazenados combustíveis e na sua área de segurança deverão ser afixadas placas com dizeres "é proibido fumar" e "explosivos", que possam ser observados por todos. Segundo a NR 20, o local deve ter proteção contra intempéries, deve ser protegido com páraraios, deve possuir sistema eficiente e adequado para combate a incêndio, devido o armazenamento de líquidos combustíveis e inflamáveis. É obrigatória a delimitação da área de risco, impedindo o ingresso de qualquer pessoa não autorizada e ter distância de, no mínimo, 50 metros do armazém, residências e postes de eletricidade (NR 16). Somente em $6 \%$ das propriedades foi encontrado extintor de incêndio nos locais de risco. Durante o processo de secagem mecânica outros riscos são observados em função do estado de conservação do painel de comando, que pode desencadear faíscas que darão origem a incêndios e riscos de choques elétricos e acidentes mecânicos, além do risco de queda de escadas, plataformas e moegas, que podem ser evitados a partir da aplicação da NR 18 e NR 26.

Após a secagem, o café deve descansar em tulhas para homogeneizar a temperatura e a umidade no interior do grão. Somente $23 \%$ das propriedades possuíam tulhas. A Tabela 4 descreve o estado de conservação das tulhas em função do nível tecnológico dos produtores.
Tabela 4 - Quantidade de tulhas em função do estado de conservação e nível tecnológico das propriedades.

\begin{tabular}{ccc}
\hline Nível & \multicolumn{2}{c}{ Estado de Conservação } \\
\cline { 2 - 3 } Tecnológico & Bom & Ruim \\
\hline Alto & 10 & 7 \\
Médio & - & 10 \\
Baixo & - & 1 \\
\hline
\end{tabular}

Observa-se que, nas propriedades classificadas em alto nível tecnológico, correspondente a $10 \%$ das propriedades visitadas, em cerca de $1 / 3$ as tulhas estavam em bom estado de conservação. Em todas as propriedades de nível médio e nas demais classificadas como nível baixo, o estado de conservação das tulhas era ruim oferecendo riscos à segurança e à saúde do trabalhador e à preservação da qualidade final do café.

Os riscos observados são desmoronamento da tulha em função do estado de conservação, queda de plataformas e escadas.

Enquanto o café permanece na fazenda a sacaria é empilhada em $87 \%$ das propriedades de forma manual (costas) e somente $13 \%$ das propriedades usam correias transportadoras, que evitam problemas ergonômicos aos trabalhadores. A NR 11 da Portaria n³.214 de 8 de junho de 1978 (BRASIL, 1978), descreve a forma correta e segura de empilhamento de sacarias. O empilhamento verificado nesses locais varia de 4 a 11 sacas empilhadas, o que de acordo com Borém (2001) está dentro do padrão recomendado para empilhamento de café, que é no máximo de 32 sacas $/ \mathrm{m}^{2}$, atingindo a altura de até 4 metros. Em $80 \%$ das propriedades as pilhas de café estavam totalmente encostadas nas paredes, absorvendo umidade com maior facilidade e em $70 \%$ das propriedades foram encontrados estrados sob o café. Em 40\% das propriedades a lona era o único material utilizado. A higiene é item de grande importância nesses locais, pois assegura a qualidade do produto e a saúde do trabalhador. Em $80 \%$ dos locais em que o café era armazenado havia vestígios e relatos da presença de roedores e pombos, animais transmissores de doenças. Em $70 \%$ das propriedades havia muita sujeira no local e vários tipos de produtos armazenados, como produtos químicos e outros cereais. Em 57\% das fazendas, foram encontradas paredes com muita sujeira e mofo.

Outro fator de risco no armazenamento são as esteiras transportadoras que levam o café das tulhas de descanso para as máquinas de beneficiamento. Essas esteiras ficam em locais sem iluminação e ventilação, muito sujo, com muita poeira em suspensão, grande 
quantidade de $\mathrm{CO}_{2}$ e caso surja no local alguma fonte de ignição como, por exemplo, um curto circuito, fumantes ou até mesmo a sonda utilizada em manutenção de máquinas, o local pode incendiar. Nesses locais também é necessário, a correta disposição do extintor de incêndio. Somente 3\% das propriedades possuíam extintor de incêndio.

O processo de beneficiamento utilizado por $70 \%$ dos entrevistados é o sistema móvel, feito por um caminhão sendo que $30 \%$ das propriedades beneficiam o café na própria fazenda. Os riscos existentes à segurança e à saúde do trabalhador são equivalentes aos riscos do secador, portanto, as normas regulamentadoras aplicáveis para o bom funcionamento da máquina beneficiadora equivalem às NR's do lavador e do secador. Os riscos à qualidade do café estão relacionados com a limpeza da máquina, que deve ser realizada a cada mudança de lote para evitar contaminação. Além de prejudicar a qualidade do café, a falta de higiene com as máquinas pode afetar também a saúde do trabalhador.

A NR 24 da Portaria n³.214 de 8 de junho de 1978, descreve o modelo de instalações que devem ser adotadas para a preservação da saúde do trabalhador.

\section{CONCLUSÕES}

Todas as etapas do processamento oferecem algum tipo de risco, devido às condições de conservação, manejo e limpeza das instalações e maquinários.

Quanto maior o nível tecnológico das propriedades maior é a percepção dos riscos por parte dos empregadores e trabalhadores, por isso, as condições de trabalho são melhores e mais seguras.

Em somente $23 \%$ das propriedades os empregadores e funcionários têm percepção dos riscos.

Devido à baixa capitalização, falta de informação e de treinamento de $70 \%$ dos entrevistados, a percepção dos riscos foi menor.

Em $87 \%$ das propriedades as instalações estão em desacordo com as conformidades das normas regulamentadoras do Ministério do Trabalho e do Emprego.

Quanto à aquisição da certificação, somente 3\% das propriedades possuem condições imediatas de obtenção da certificação.

\section{REFERÊNCIAS BIBLIOGRÁFICAS}

BINDER, M. C. P.; WLUDARSKI, S. L.; ALMEIDA, I. M. de. Estudo da evolução dos acidentes do trabalho registrados pela Previdência Social no período de 1995 e 1999, em Botucatu - SP. Caderno de Saúde Pública, Rio de Janeiro, v. 17, n. 14, jul./ago. 2001.

BORÉM, F. M. Processamento de produtos agrícolas. Lavras: UFLA, 2001. 150 p.

BRASIL. Ministério do Trabalho. Portaria n. 3067, de 12 de abril de 1988. Brasília, DF, 12 abr. 1988.

BRASIL. Ministério do Trabalho. Portaria n. 3214, de 8 de junho de 1978. Brasília, DF, 8 jun. 1978.

CHALFOUN, S. M. de S. et al. Programa de segurança na cadeia produtiva do café arábica. Lavras: UFLA, 2003. 54 p.

GLOBAL EXCHANGE. Fair trade. 2004. Disponível em: <http//www.globalexchange.org/campaigns/fairtrade/ coffee $>$. Acesso em: 10 jan. 2005.

LACERDA, G. Mercado internacional é promissor. 1998. Disponível em: <http//www.agr.féis.unesp.br/café.htm>. Acesso em: 10 jan. 2005.

MACHADO, J. M. H.; GOMES, C. M. Acidentes de trabalho: uma expressão da violência social. Caderno de Saúde Pública, Rio de Janeiro, v. 10, 1994. Suplemento 1.

PANALIMENTOS. Boas praticas de manufatura (GMP) e análise de perigos e pontos críticos de controle (HACCP). 2003. Disponível em: <http://www.panalimentos.com.br〉. Acesso em: 2 abr. 2004.

PERES, F.; LUCCA, S. R. de; PONTE, L. M. D. da; RODRIGUES, K. M.; ROZEMBERG, B. Percepção das condições de trabalho em uma tradicional comunidade agrícola em boa Esperança, Nova Friburgo, Rio de Janeiro, Brasil. Caderno de Saúde Pública, Rio de Janeiro, v. 20, n. 4, jul./ago. 2004. 